\title{
An addition of medium-dose ATG to conditioning regimens favours the long-term survival of patients with allogeneic hematopoietic stem cell transplantation
}

\author{
Bingyi Wu*, Chaoyan Song, Zhigang Lu, Kunyuan Guo, Yingzhi He, Sanfan Tu, Shaojuan Pan, \\ Can Sun, Junyong Fang
}

Department of Haematology, Zhujiang Hospital, Southern Medical University, Guangzhou, China;

*Corresponding Author: wubingyi@yahoo.com.cn

Received 1 October 2012; revised 3 November 2012; accepted 5 December 2012

\begin{abstract}
Long-term survival of 116 leukemia/MDS patients received allo-SCT conditioned by a regimen with ATG-F or without ATG-F was analysed, together with the impact of ATG-F on the long-term survival, GVHD and disease relapse. Seventy patients received an ATG-F containing conditioning regimen $F B C A$, and 46 patients received a non-ATG-F FBC regimen. The FBCA regimen was associated with a 5 -year survival of $65.4 \%$ in the complete HLA-matched group and $39.3 \%$ in the HLA-mismatched group. The difference between the two groups was significant $(P=0.012)$. For the $\mathrm{FBC}$ conditioning regimen, the 5-year overall survival of HLA-matched patients and the HLAmismatched patients was $34.2 \%$ and $24.2 \%$ respectively $(P=0.216)$. The incidence of cGVHD was $32.9 \%$ and $83.6 \%$ in the FBCA and FBC condition regimen group respectively. Only $2.9 \%$ of the cases showed extensive cGVHD in the FBCA group while it was $69.4 \%$ in the FBC group $(P=0.00)$. Multivariate analysis indicated that relapse was related to the disease status and HLA typing, but unrelated to the conditioning regimens whether or not ATG-F was used (HR $0.54, P=0.109$ ). We conclude that the addition of ATG-F to conditioning regimen favours the longterm survival of allo-SCT.
\end{abstract}

Keywords: Hematopoietic Stem Cell

Transplantation; Long-Term Survival; Anti-Human Lymphocyte Globulin

\section{INTRODUCTION}

Allogeneic hematopoietic stem cells transplantation
(allo-SCT) is a curative therapy for hematological malignancy. Long-term survival of allo-SCT after first complete remission (CR1) of acute leukemia has reached $50 \%$ - 70\% [1,2]. Even with refractory acute myeloid leukemia, the long term survival of allo-SCT can reach $30 \%$. [3] However due to HLA-discrepancies between donor and recipient, the Graft Versus Host Disease (GVHD) continues to be the major source of morbidity and mortality following allo-SCT, and the risk of severe GVHD increases with the level of HLA mismatches between recipient and donor [4]. In one study, the rate of acute GVHD (aGVHD) increased from $29 \%$ for recipients of HLA genotypically identical sibling grafts to $63 \%$ for recipients with one antigen incompatible unrelated donor grafts [5]. In the standard myeloablative conditioning allo-SCT setting using HLA-matched related or unrelated donors, the classical prophylaxis of GVHD consists of the administration of a calcineurin inhibitor combined with low-dose methotrexate (MTX). This regimen reduces the incidence of grade [2-4] acute and chronic GVHD (cGV HD) after allo-SCT using matched-related donors to $35 \%$ and $45 \%[6,7]$, whereas these incidences are $60 \%$ and $70 \%$ in the context of matched unrelated donors (MUD) transplants [8]. Attempts are therefore needed to improve GVHD prophylaxis in allo-SCT.

A study reported by Grüllich [9] showed that anti-T lymphocyte globulin (ATG) could not only induce apoptosis in T-lymphocytes, B-lymphocytes, natural killer (NK)-cells, and monocytes but also induce human leukemia cell lines such as Jurkat, Daudi, DG-75 (lymphoblastic), and K562, HL-60, KG1, and U937 apoptosis. Hematopoietic stem cells (HSC), in contrast, were apoptosis resistant and could be growth stimulated by lowdose ATG in the presence of bystander cells. Those studies suggest that ATG not only might be a strong immune suppressor but also could support HSC engraftment and 
influence the allo-SCT outcome positively.

Remberger M. et al. [10] reported that using polyclonal anti-T-cell globulin as part of the conditioning regimen of allo-SCT, reduced the risk of aGVHD of grades II-IV and cGVHD remarkably. Finke et al. [11] reported that rabbit anti-T lymphocyte globulin could achieve good results in the prevention of aGVHD in unrelated or HLA mismatched allo-SCT in 2003. And Finke [12] reported in 2009 that 201 patients with hematologic malignancies were randomized to receive cyclosporine $\mathrm{A}(\mathrm{CyA})$ and MTX with or without additional ATG-fresenius (ATG-F). The stem cell source was peripheral blood $(n=164 ; 82 \%)$ or bone marrow ( $\mathrm{n}=37 ; 18 \%)$, the donor type was unrelated, and the conditioning regimen was myeloablative. The analysis comprised 103 ATG-F patients and 98 controls. The cumulative incidence of aGVHD grade III-IV was $11.7 \%$ in the ATG-F group versus $24.5 \%$ in the control group $(\mathrm{P}=0.054)$, and the cumulative incidence of aGVHD grade II-IV was $33 \%$ in the ATG-F group versus $51 \%$ in the control group $(\mathrm{P}=0.011)$. The 2 -year cumulative incidence of extensive cGVHD was $12.2 \%$ versus $42.6 \%(\mathrm{P}=0.0001)$. It has been known that the addition of ATG to conditioning regimens can not only reduce the incidences of aGVHD and cGVHD significantly but also facilitate engraftment in allo-SCT [13-15]. Despite promising result in GVHD prevention and graft facilitation, ATG use is greatly limited by multiple side effects. It has been reported that addition of ATG to conditioning regimens could delay the immune reconstitution in vivo and might increase the risk of leukemia relapse. Cytomegalovirus (CMV) and Epstein Barr virus (EBV) reactivation, lymphoproliferative disorders $[16,17]$ are reportedly increased with the use of ATG. The ideal dose of ATG that exerts the highest effect in conditioning regimens while having the lowest toxicity has not yet been defined and the form and preparations of anti-T cell globulins from immunizing different $\mathrm{T}$ cells affect the results. Recently R. Devillier et al. [18] reported increasing the rabbit ATG dose in reduced intensity conditioning from 2.5 to $5 \mathrm{mg} / \mathrm{kg}$ reduced aGVHD and cGVHD for patients with myeloid malignancies undergoing allo-SCT. An ATG dose of $5 \mathrm{mg} / \mathrm{kg}$ in the setting of reduce intensity conditioning regimen (RIC) seems to provide a good balance between antitumor effect and GVHD prevention without any significant increased relapse rate.

We started to add ATG-F to the conditioning regimen since 1999 and established a conditioning regimen including fludarabine, busulfan, cyclophosphamide and ATGF (FBCA) for transplantation in leukemia patients. A dose of $2.5 \mathrm{mg} / \mathrm{kg} \times 5$ days of ATG-F was added to the conditioning regimen for HLA identical patients and 5.5 $\mathrm{mg} / \mathrm{kg} \times 5$ days for HLA mismatched patients. The longterm survival, relapse rate and incidence of GVHD with leukemia/myelodysplastic syndrome (MDS) in patients receiving this FBCA conditioning regimen were analysed retrospectively. The results were compared with the conditioning regimen without ATG-F, to observe the impact of adding ATG-F to the conditioning regimen on longterm survival, the incidence of GVHD and the disease relapse rate in leukemia/MDS patients.

\section{MATERIALS AND METHOD}

\subsection{Data Collection}

Data from leukemia and MDS patients who received allogeneic hematopoietic stem cells transplantation in our department from 1 January 1999 to 31 December 2010 were collected. The diagnoses of leukemia and MDS were confirmed by bone marrow cytological examinations, chromosome analysis, immunological typing and molecular biological examinations. For historical reasons, data of some cases were incomplete.

\subsection{Inclusion Criteria}

Inclusion criteria included patients with leukemia and MDS aged between 12 and 60 years old who underwent allogeneic hematopoietic stem cell transplantation and achieved hematopoietic reconstitution with survival longer than 1 month. The exclusion criteria included age below 12 years or above 60 years, transplantation failure, unsuccessful hematopoietic reconstitution, or death within 1 month.

\subsection{Characteristics of the Patients}

From 1 January 1999 to 31 December 2010, a total of 116 patients with leukemia and MDS received allogeneic hematopoietic stem cell transplantation, of whom 75 cases had acute leukemia. 37 had acute lymphoblastic leukemia (ALL), 38 had acute myeloid leukemia (AML), 25 cases had chronic leukemia and 16 cases had MDS. CR1 in 71 cases, second complete remission (CR2) in 14 cases, third complete remission (CR3) in 5 cases, and no remission (NR) in 26 cases. Data details are shown in Table 1. In sixty-nine cases there was a complete HLA match and in 47 cases of the HLA was mismatched. The FBCA conditioning regimen was approved by the board of ethic of our hospital. All patients in the group written informed consent, in accordance with the Declaration of Helsinki.

\subsection{Transplantation Procedures}

In this series, 70 patients receive ATG-F as part of the conditioning regimen FBCA, whereas 46 patients received no ATG-F FBC conditioning regimen. The FBC conditioning regimen consisted of fludarabine $25 \mathrm{mg} / \mathrm{M}^{2}$ $\times 5 \mathrm{~d}$, busulfan $4 \mathrm{mg} / \mathrm{kg} \times 4 \mathrm{~d}$ and cyclophosphamide 60 $\mathrm{mg} / \mathrm{kg} \times 2 \mathrm{~d}$. Based on the fludarabine, busulfan and cy- 
Table 1. Patients' characteristics.

\begin{tabular}{lc}
\hline Patients' characteristics & Numbers (n) \\
\hline Median Age (year old range) & $27(12-58)$ \\
\hline Diagnosis & 38 \\
AML & 4 \\
$\quad$ M1 & 17 \\
M2 & 6 \\
M4 & 8 \\
M5 & 37 \\
ALL & 25 \\
CML & 16 \\
MDS &
\end{tabular}

Status at transplantation (n)

\begin{tabular}{lc}
$\mathrm{CR} 1$ & 71 \\
$\mathrm{CR} 2$ & 14 \\
$\mathrm{CR} 3$ & 5 \\
$\mathrm{NR}$ & 26 \\
\hline Chemotherapy before transplantation & $4(2-17)$ \\
Mean (cycles) & \\
\hline Karotype & 10 \\
Favourable (n) & 36 \\
Intermediate (n) & 38 \\
High risk (n) & 32 \\
ND
\end{tabular}

The time from diagnosis to transplantation

Median (months) $\quad 8 \pm 2.86 \mathrm{~m}$

Chemotherapy before transplantation

\begin{tabular}{lc} 
Mean (cycles) & $4(2-17)$ \\
\hline Donor-recipient HLA locus mismatched & 47 \\
A & 3 \\
A,B & 18 \\
A,DRB1 & 12 \\
B & 2 \\
B,DRB1 & 8 \\
A,B,DRB1 & 4 \\
\hline
\end{tabular}

\begin{tabular}{ll}
\hline Donor-recipient HLA-matched (n) & 69 \\
A,B,DRB1 & 45 \\
A,B,C,DRB1,DQ,DP & 24
\end{tabular}

CMV donor/recipient serostutus (n)

$\begin{array}{lc}+/+ & 96 \\ +/- & 5 \\ -/+ & 6 \\ -/- & 9\end{array}$

\section{Graft source}

PBSCs (n)

80

PBSCs+BM (n)

36

Abbreviation: AML: acute myeloid leukemia; ALL: acute lymphobastic leukemia; MDS: myelodysplastic syndrome; CML: chronic myeloid leukemia; CR1: the first complete remission; CR2: the second complete remission; CR3: the third complete remission; NR: no remission; ND: no detection; PBSCs: pheripherial blood stem cells; BM: bone marrow. clophosphamide regimen, different doses of ATG-F were administered before transplantation to form an FBCA conditioning regimen. The dose of ATG-F was $2.5 \mathrm{mg} / \mathrm{kg}$ $\times 5$ for the HLA identical patients and $5.5 \mathrm{mg} / \mathrm{kg} \times 5$ for the HLA mismatched patients. 50 patients received busulfan by oral administration. In 76 patients busulfan was administered via intravenous injection at a dose of 3.2 $\mathrm{mg} / \mathrm{kg} \times 4 \mathrm{~d}$. The patients' characteristics in respect of different conditioning regimens are shown in Table 2. The day of cell infusion was designated as day 0 . A mean of $5.0 \times 10^{8}$ (range $\left.2.5-8.6 \times 10^{8}\right) / \mathrm{kg}$ GranulocyteColony Stimulating Factor (G-CSF) mobilized mononuclear cells (MNCs) was infused. GVHD prophylaxis [19] included CyA and a short course of MTX. The transplantation was carried out under full environmental protecting conditions. Other supportive care included blood transfusion and gamma globulin infusion. CMV pre-emptive treatment [20] and anti-fungal prophylaxis [21] were carried out conventionally. The diagnoses of acute and chronic GVHD were in accordance with methods reported in literature [22-24].

\subsection{HLA Typing}

HLA Type I and Type II antigens were detected serologically prior to 2004. After 2004 the HLA Type I and Type II antigens were detected with the Sequence-Specific Primer (SSP) method.

\subsection{Follow-Up}

Routine blood checks were taken once a week within the first half year following the transplantation of the hematopoietic stem cells. A bone marrow smear and leukemia fusion genes were checked once every month. CyA was discontinued at 6 months after transplantation in HLA full match patients and at 1 year for HLA mismatched patients.

\subsection{Study Endpoint}

The short-term endpoint of the study is the influence of ATG-F on the relapse of post-transplantation leukemia, defined as the time from transplantation to hematological recurrence of the leukemia or MDS after the transplantation. The secondary endpoint was the influence of ATG-F on long-term survival, defined as the time from the transplantation to the most recent follow-up when the patient was still alive. The time of statistical analysis was January 2012.

\subsection{Statistical Analysis}

The SSPS17 statistic software was used. The survival analysis was performed with the Kaplan-Meier method. Univariate and multivariate Cox proportional hazard regression models were used to evaluate variables which 
Table 2. Comparison of patients' characteristics in different conditioning regimen group.

\begin{tabular}{|c|c|c|c|}
\hline \multirow{2}{*}{ Characteristics of patients } & \multicolumn{2}{|c|}{ Conditioning regimen } & \multirow{2}{*}{$\mathrm{P}$} \\
\hline & FBCA & FBC & \\
\hline Median age (year old) & $26(12-58)$ & $33(15-56)$ & \\
\hline \multicolumn{4}{|l|}{$\overline{\text { Sex }}$} \\
\hline Male (n) & 48 & 30 & \\
\hline Female (n) & 22 & 16 & 0.970 \\
\hline \multicolumn{4}{|l|}{ Diagnosis (n) } \\
\hline AML & 19 & 19 & \multirow{8}{*}{0.398} \\
\hline M1 & 1 & 3 & \\
\hline M2 & 13 & 7 & \\
\hline M4 & 2 & 4 & \\
\hline M5 & 3 & 5 & \\
\hline ALL & 22 & 15 & \\
\hline CML & 14 & 11 & \\
\hline MDS & 15 & 1 & \\
\hline \multicolumn{4}{|l|}{ Statu at transplantation (n) } \\
\hline CR1 & 44 & 27 & \multirow{4}{*}{0.256} \\
\hline CR2 & 5 & 9 & \\
\hline CR3 & 3 & 2 & \\
\hline NR & 18 & 8 & \\
\hline $\begin{array}{l}\text { Chemotherapy before } \\
\text { transplant Mean (cycles) }\end{array}$ & $4(2-17)$ & $4(1-10)$ & 0.748 \\
\hline $\begin{array}{l}\text { The time from diagnosis to } \\
\text { transplant Median(month) }\end{array}$ & $8 \pm 2.86$ & $8.18 \pm 0.753$ & 0.923 \\
\hline $\begin{array}{l}\text { Donor-recipient HLA } \\
\text { mismatched (n) }\end{array}$ & 37 & 10 & 0.02 \\
\hline $\begin{array}{l}\text { Donor-recipient } \\
\text { HLA-matched (n) }\end{array}$ & 33 & 36 & 0.917 \\
\hline
\end{tabular}

could affect. Leukemia relapse and survival rate analyses compared between two groups were tested with the $x^{2}$ test.

\section{RESULTS}

\subsection{Addition of ATG-F to Preconditioning Regimens Favours the Long-Term Survival}

Apart from 1 case who failed to graft in the FBC conditioning regimen group, 115 cases were entered into the statistical analysis. All 115 patients achieved successful hematopoietic reconstitution. Of these patients, 56 patients died of various causes and 68 patients still survive, with a median survival time at 26.8 months. The outcomes after transplantation with different conditioning regimen see Table 3. After transplantation, 24 of 26 patients who had not experienced remission before the transplantation achieved hematological remission giving a complete remission rate of $92.3 \%$. The 2 year overall survival and 2 years disease-free survival were both
Table 3. Clinical outcomes after HSCT with different conditioning regimen.

\begin{tabular}{lccc}
\hline \multirow{2}{*}{ Clinical outcomes } & \multicolumn{2}{c}{ Conditioning regimen } & P \\
\cline { 2 - 3 } & FBCA & FBC & \\
\hline Graft failure (n) & 0 & 1 & \\
2 years OS (\%) & 69.2 & 39.3 & 0.04 \\
2 years DFS (\%) & 9.2 & 39.3 & 0.04 \\
Cause of death (n) & & & \\
Relapse & 13 & 14 & NS \\
GVHD & 6 & 6 & NS \\
Infection & 13 & 4 & 0.02 \\
\hline
\end{tabular}

$50.6 \%$. The 5-year overall long-term survival and disease-free survival were both $45.0 \%$ (Figure 1). A significant difference was found between the long-term survival of patients receiving different conditioning regimens. The addition of ATG-F to the conditioning regimen had an effect on the long-term survival both of the complete HLA identical transplants and the HLA mismatched transplants. The survival curves of the FBCA group and the FBC groups are shown in Figures 2-5. Of the patients receiving the FBCA conditioning regimen, the 2 -year survival and the 5-year survival of the complete HLA matched transplant were $69.2 \%$ and $65.4 \%$ respectively, and the 2-year survival and the 5-year survival of the HLA mismatched transplant were $39.3 \%$ and $39.3 \%$ respectively. On the other hand, in the patients receiving the FBC conditioning regimen, the 2-year survival of the complete HLA-matched patients and the HLA-mismatched patients were $50.9 \%$ and $24.2 \%$ respectively. The 5 -year overall survival of HLA-matched patients and the HLA-mismatched patients were $34.4 \%$ and $24.2 \%$ respectively. There is a difference between the two conditioning regimens in terms of overall survival of patients with both HLA full matched transplants and HLA mismatched transplants $(\mathrm{P}=0.012)$. The results indicate that an addition of ATG to the fludarabine, busulfan and cyclophosphamide conditioning regimen may improve the long-term survival and the disease-free survival of the transplantation patients whether they are completely HLAmatched or HLA-mismatched.

\subsection{Addition of ATG to Conditioning Regimen Reduces the Incidence of Extensive cGVHD}

The cumulative incidence of aGVHD in the FBC group was $63.3 \%$. The grade $3-4$ aGVHD was $21.1 \%$ this group. On the other hand, the cumulative incidence of aGVHD was $50.6 \%$ in the FBCA group, with grade 3 4 aGVHD in only $6.3 \%$. The difference of the incidence 


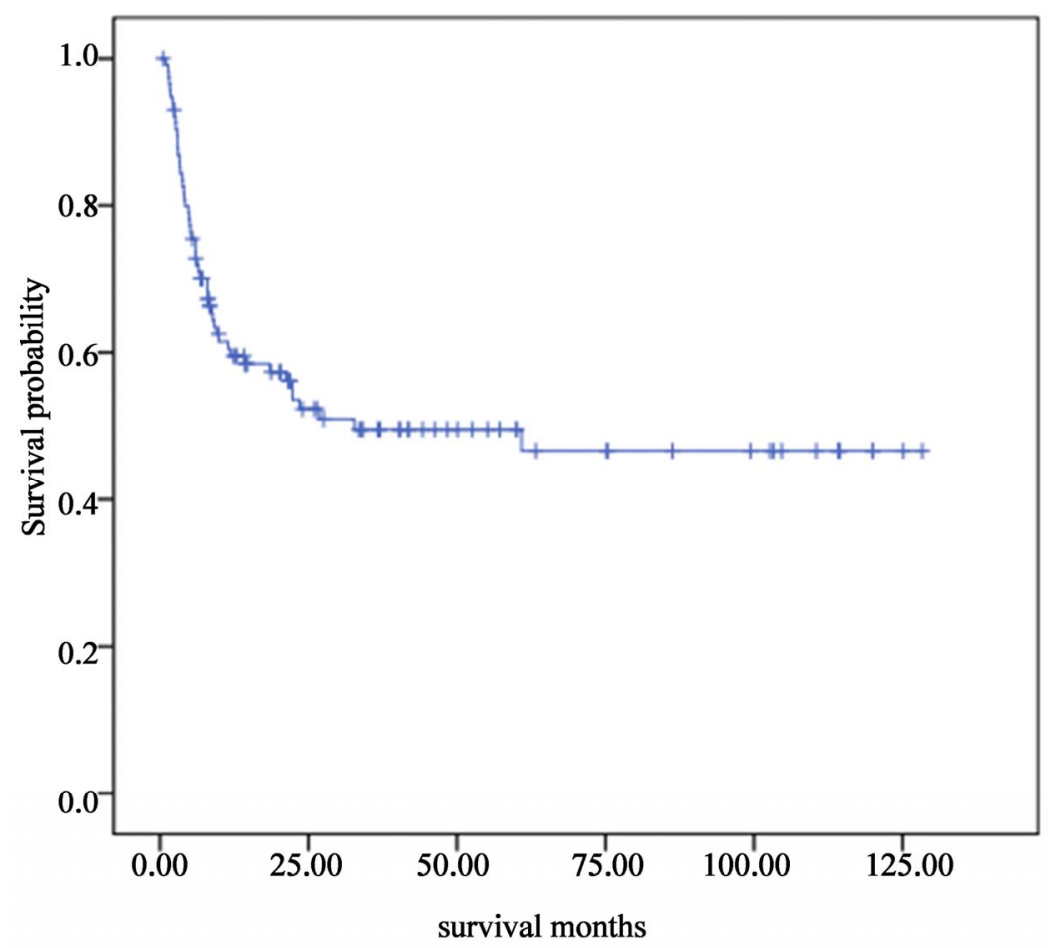

Figure 1. Overall long-term survivals of 115 patients who underwent allogeneic stem cells transplantation from January 1999 to December 2010.

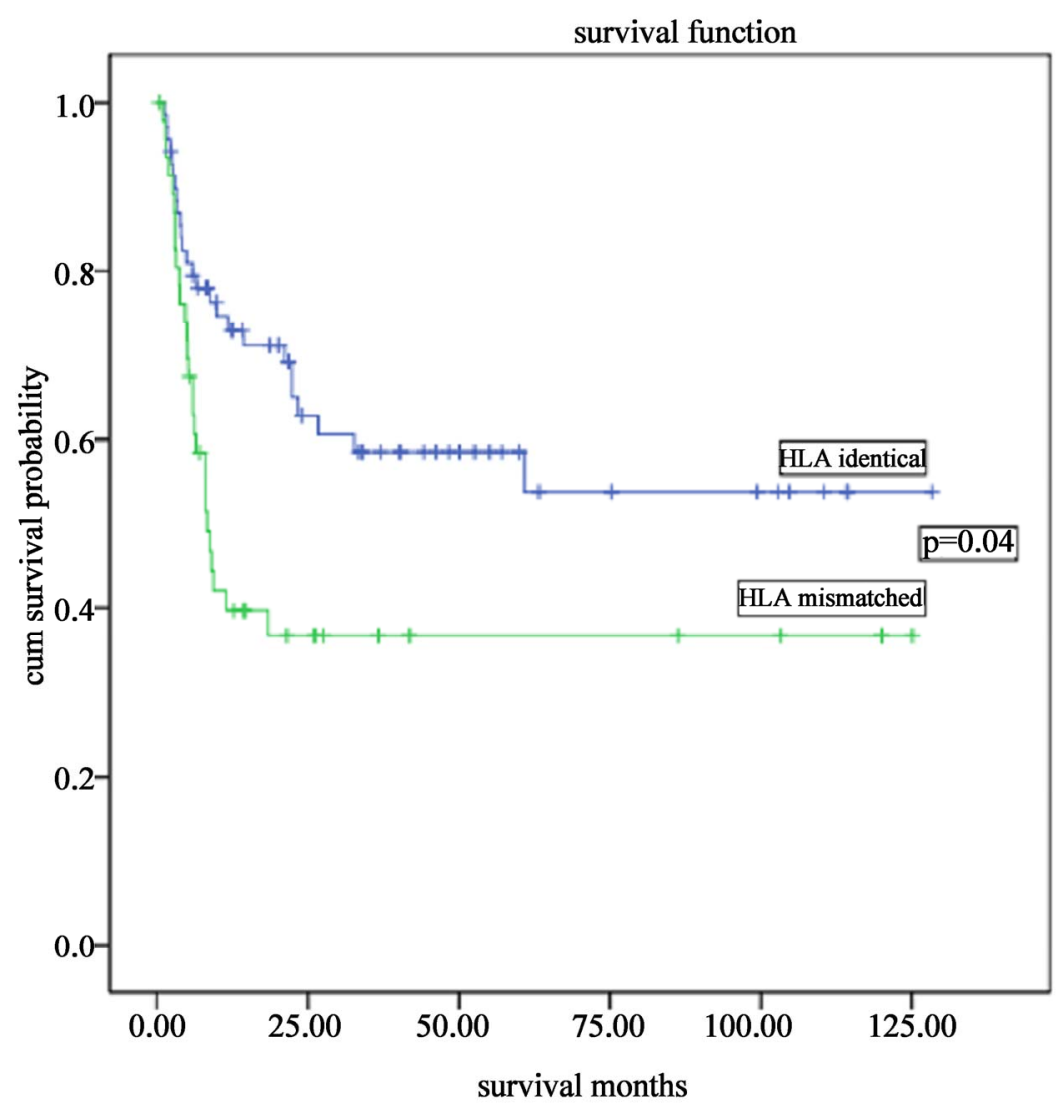

Figure 2. Overall survivals of complete HLA-matched and HLA mismatched transplantations with the FBCA conditioning regimen. 


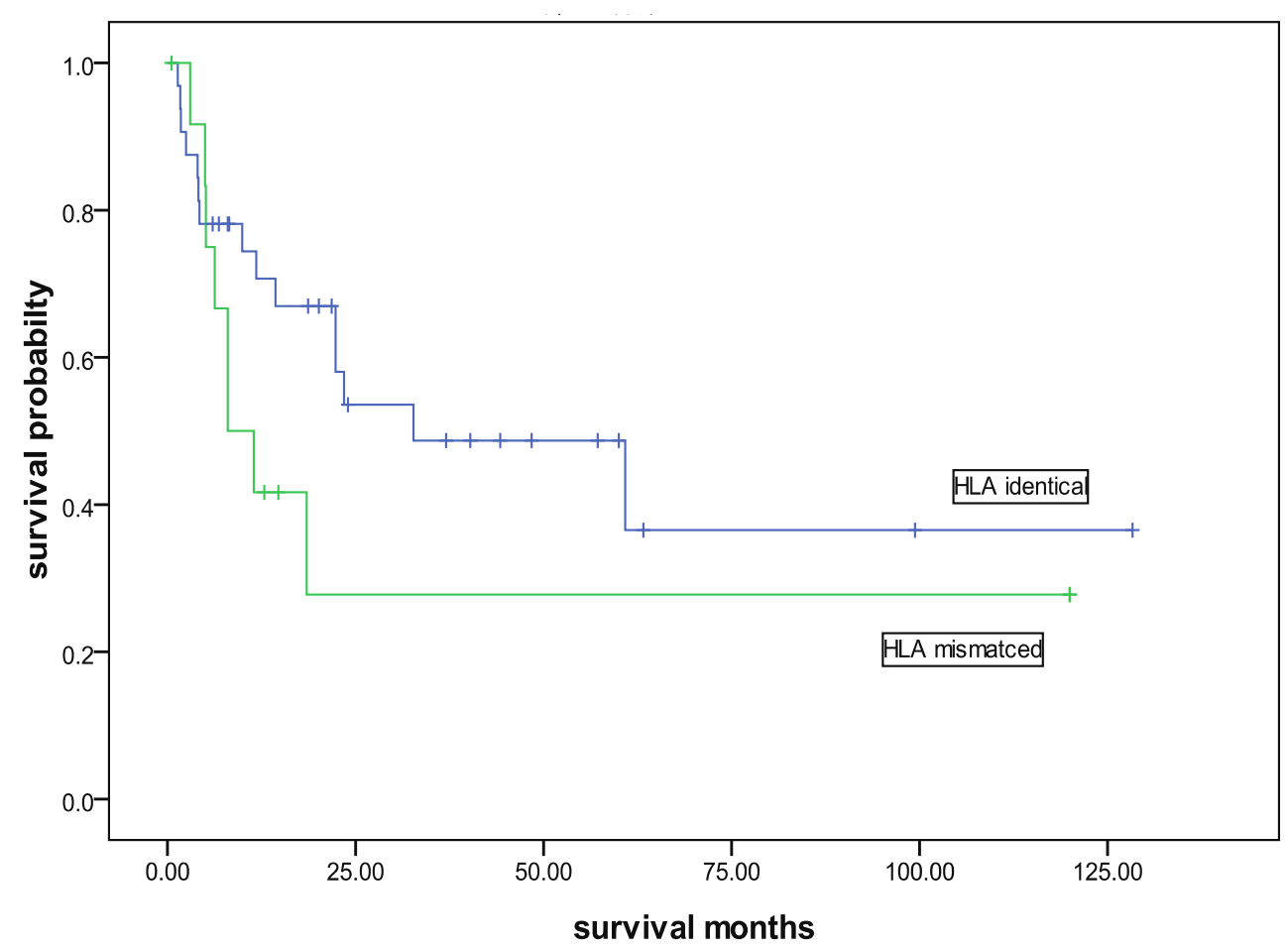

Figure 3. Overall survivals of complete HLA identical and HLA mismatched transplantations with the FBC conditioning patients.

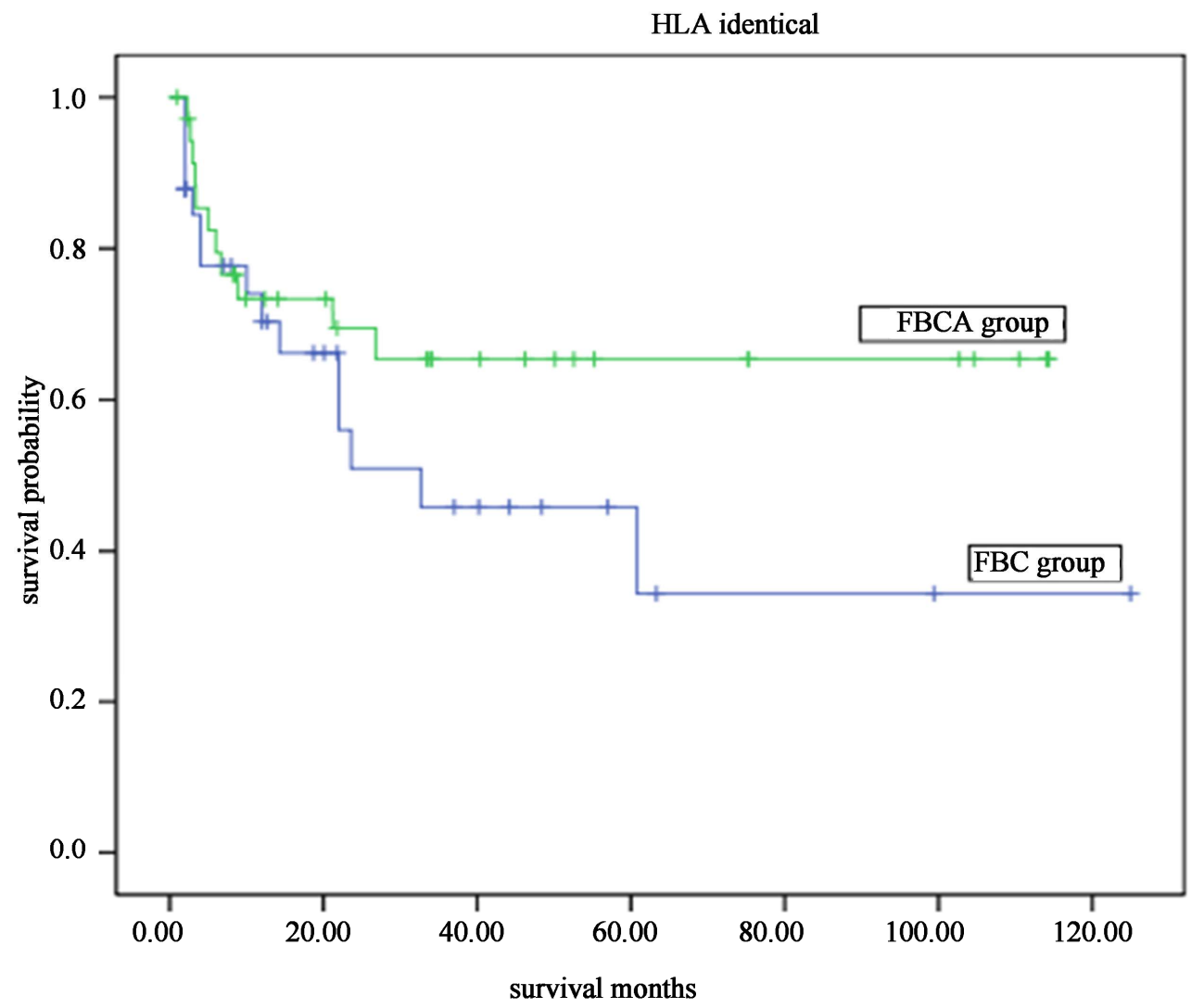

Figure 4. The overall survival of patients received HLA identical transplant with different the FBCA and $\mathrm{FBC}$ conditioning regimen. 


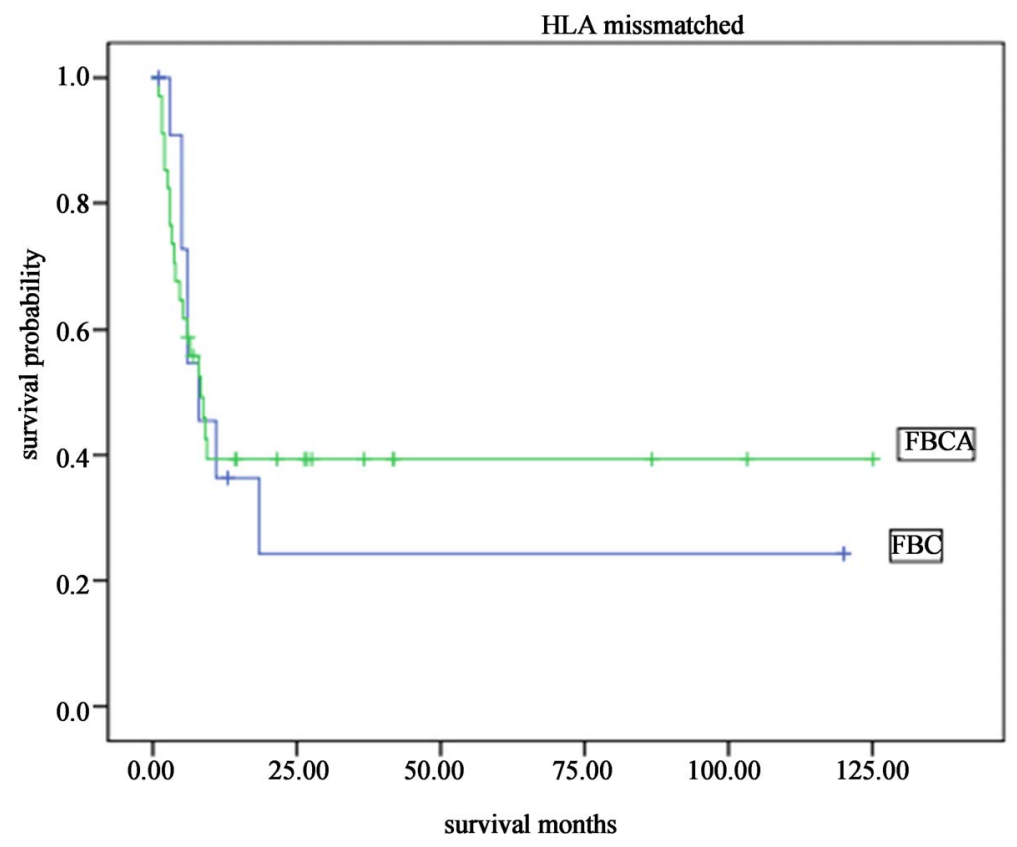

Figure 5. The overall survival of patients received HLA mismatched transplant with different the FBC and FBCA conditioning regimen.

of aGVHD especially severe aGVHD between FBC and FBCA conditioning regimen was significantly $(\mathrm{P}=0.022)$. Chronic GVHD occurred in 23 cases of the FBCA group and the incidence of cGVHD was $32.9 \%$. Whereas 30 cases of cGVHD occurred in the FBC group and the incidence of cGVHD was $83.3 \%$. Comparing the two groups showed a significant difference $(P=0.00)$, see Table 4 . The degrees of severity of the cGVHD were also different. In the FBC conditioning regimen group, the cGVHD were mostly extensive, with an incidence of $69.4 \%$. However, in the FBCA group, the incidence of extensive cGVHD was only $2.9 \%$, and limited cGVHD occurred in $30 \%$ of patients. Oral ulcers and raised ALP in liver function tests, with no impact on the quality of life in these patients. The median time to the occurrence of cGVHD in the FBC group was 110 days and in some patients the cGVHD was transformed from aGVHD. In the FBCA group, the median time to the occurrence of cGVHD was 150 days, indicating that the addition of ATG to the conditioning regimen could postpone the occurrence of cGVHD and reduce its severity.

\subsection{Addition of ATG to Conditioning Regimen Did Not Increase the Risk of Relapse of Leukemia}

Long-term follow-up was carried out in all transplanttation patients and the longest follow-up period was 125 months. Thirty-three cases of leukemia relapsed, with a relapse rate of $28.4 \%$. Of these 6 patients achieved complete remission by donor lymphocyte infusion. Overall,
Table 4. Incidences of aGVHD and cGVHD in the different conditioning regimen groups.

\begin{tabular}{cccc}
\hline \multirow{2}{*}{ Incidences of GVHD } & \multicolumn{2}{c}{ Conditioning regimen } & \multirow{2}{*}{ P } \\
\cline { 2 - 3 } & FBC & FBCA & \\
\hline aGVHD & & & 0.022 \\
Grade I-II (n)\% & $(16) 42.1$ & (29) 45.3 & \\
Grade III-IV (n)\% & $(8) 21.2$ & (4) 6.3 & \\
Total \% & 63.3 & 51.6 & \\
cGVHD & & & 0.00 \\
Limited (n)\% & (5) 10.9 & (21) 30.0 & \\
Extensive \% (n) & (25) 69.4 & (2) 2.9 & \\
Total \% & 83.3 & 32.9 & \\
\hline
\end{tabular}

the post-transplantation relapse was relevant to the status and subtypes of the diseases prior to the transplantation. In the 21 cases with NR patents before transplantation, 15 had MSD and 6 had leukemia, 5 cases of leukemia relapsed after transplantation. The relapse rate in the pretransplantation CR1 leukemia group was 20.6\%, and it was $61.5 \%$ in the partial remission (PR) patients, and $46.2 \%$ in the CR2 patients. The differences between the groups were significant $(\mathrm{P}=0.025)$. The relapse rate in the patients receiving $\mathrm{FBCA}$ conditioning regimen was $25.7 \%$, and the relapse rate in the patients receiving $\mathrm{FBC}$ conditioning regime was $32.6 \%$. The median time to relapse was 6 months after transplantation, with the longest time being 12 months. Univariate correlation analyses were carried out between the relapse and the pre-trans- 
plantation disease status, the time of transplantation, whether or not AGT was added to the conditioning regimen, HLA typing and karyotypes. The results showed that relapse was significantly related to the status of the diseases at the time of transplantation $(\mathrm{HR}=1.581, \mathrm{P}=0.024)$ and the subtype of the disease ( $\mathrm{HR}=0.880, \mathrm{P}=0.036)$, but was not related to the conditioning regimen. Multivariate analysis indicated that post-transplantation relapse of leukemia was significantly related to the condition of the patient's diseases $(\mathrm{HR}=1.894, \mathrm{P}=0.026)$ and the HLA typing $(\mathrm{HR}=3.667, \mathrm{P}=0.010)$, but not related to the type of conditioning regimen. For correlation variant analysis, see Table 5.

\section{DISCUSSION}

We [25] modified the classical busulfan and cyclophosphamide conditioning regimen for allogeneic hematopoietic stem cells transplantations in 1998. By using fludarabine in the conditioning regimen to increase immunosuppression, the engraft rates were increased. No engraft failure occurred with the conditioning regimen FBC. Furthermore, no T cell-depleted HLA haploididentcial transplantation was successfully achieved with the FBC conditioning regimen. However, the incidence of acute and chronic GVHD was still high. The frequency of aGVHD III-IV was $36 \%$ and cGVHD was high as $83 \%$. The addition of ATG to the conditioning regimen not only reduced

Table 5. Cox univariate and multivariate analyses of the factors relevant to relapse.

\begin{tabular}{|c|c|c|c|c|}
\hline \multirow{3}{*}{$\begin{array}{c}\text { Factors relevant } \\
\text { to relapse }\end{array}$} & \multicolumn{2}{|c|}{$\begin{array}{l}\text { Cox } \\
\text { multivariate analysis }\end{array}$} & \multicolumn{2}{|c|}{$\begin{array}{l}\text { Cox } \\
\text { univariate analysis }\end{array}$} \\
\hline & HR & & HR & \\
\hline & $(95 \% \mathrm{CI})$ & $\mathrm{P}$ & $(95 \% \mathrm{CI})$ & $\mathrm{P}$ \\
\hline Age & $\begin{array}{c}1.034 \\
0.987-1.0830\end{array}$ & 0.156 & $\begin{array}{c}1.014 \\
0.983-1.045\end{array}$ & 0.384 \\
\hline cGVHD & $\begin{array}{c}0.499 \\
0.167-1.490\end{array}$ & 0.213 & $\begin{array}{c}0.899 \\
0.560-1.442\end{array}$ & 0.658 \\
\hline $\begin{array}{l}\text { Disease status } \\
\text { at transplant }\end{array}$ & $\begin{array}{c}1.894 \\
1.136-3.156\end{array}$ & 0.026 & $\begin{array}{c}1.581 \\
1.032-2.352\end{array}$ & 0.024 \\
\hline $\begin{array}{l}\text { Conditioning } \\
\text { regimen }\end{array}$ & $\begin{array}{c}0.487 \\
0.178-1.767\end{array}$ & 0.217 & $\begin{array}{c}0.838 \\
0.581-1.210\end{array}$ & 0.838 \\
\hline HLA matching & $\begin{array}{c}3.66 \\
1.358-9.903\end{array}$ & 0.010 & $\begin{array}{c}1.827 \\
0.874-3.8210\end{array}$ & 0.109 \\
\hline ATG & $\begin{array}{c}0.97 \\
0.044-21.323\end{array}$ & 0.985 & $\begin{array}{c}1.254 \\
0.598-2.631\end{array}$ & 0.548 \\
\hline $\begin{array}{l}\text { Subtype of } \\
\text { disease }\end{array}$ & $\begin{array}{c}0.912 \\
0.776-1.072\end{array}$ & 0.264 & $\begin{array}{c}0.88 \\
0.751-0.992\end{array}$ & 0.036 \\
\hline $\begin{array}{l}\text { Time from } \\
\text { disease onset to } \\
\text { transplant }\end{array}$ & $\begin{array}{c}1.000 \\
1.00-1.000\end{array}$ & 0.099 & $\begin{array}{c}1.00 \\
1.00-1.00\end{array}$ & 0.578 \\
\hline
\end{tabular}

the incidence of cGVHD but also the severity of cGVHD. The incidence of cGVHD was only $33.3 \%$ in the FBCA conditioning regimen group, and most of the cGVHD in this group were limited, whereas the incidence of the chronic GVHD in the FBC conditioning regime group was as high as $83.3 \%$ and $69.4 \%$ of these were extensive cGVHD. These results are consistent with those reported by Bacigalupo [26] and systematic reviewed by Kumar [27].

The statistical analysis also indicated that an addition of ATG-F to the conditioning regimen could prolong survival. In the FBCA conditioning regimen group, whether the transplantation was HLA identical or HLA haploidentical, the long-term survival was significant higher than that with the FBC conditioning regimen group. The 5-year survival of the complete HLA identical cases was $79.1 \% \pm 8.78 \%$, and the 5 -year survival of the HLA mismatched patients was $52.0 \% \pm 10.3 \%$. Our results are consistent with those reported by Kim [28] 2009 and Mohty [29] 2010 in HLA-MUR transplantation.

An increased risk of relapse of leukemia has been reported with the ATG-F conditioning regimen. Remberger et al. [10] reported polyclonal ATG as part of the conditioning regimen in 56 children with allogeneic stem cell transplantation. Relapse rates were $42 \%$ in Remberger's study. It seemed that the relapse rate was higher when ATG was added to the conditioning regimen. Moreover, an increase in the risk of relapse of leukemia with an ATG conditioning regimen has been reported by other authors [30]. On the other hand it has been indicated that the use of polyclonal ATG as part of conditioning prior to Allo-SCT improved the survival rate [15]. The important point is how to balance high efficacy of ATG and low toxicity. The toxicity of ATG increases with the dose of ATG. We used a dose of $2.5 \mathrm{mg} / \mathrm{kg} / \mathrm{d} \times 5 \mathrm{~d}$ ATG-F for the complete HLA-matched donor transplantation and a dose of $5.5 \mathrm{mg} / \mathrm{kg} / \mathrm{d} \times 5 \mathrm{~d}$ for the HLA mismatced donor transplantation. A total of 33 patients of leukemia in 115 patients relapsed, giving a relapse rate of $28.4 \%$. The relapse rate in the patients receiving FBCA conditioning regimen was $25.7 \%$, and the relapse rate in the patients receiving $\mathrm{FBC}$ conditioning regime was $32.6 \%$. Multivariate analysis showed that ATG in the conditioning regimen was not related to relapse of the disease. On the other hand the disease status at the time of transplantation was related to the relapse rate. This finding is consistent with previous report $[13,29]$.

\section{ACKNOWLEDGEMENTS}

We acknowledge the contribution to this study made by the medical and nursing staff of the Laminar Flow Ward and Blood Bank of the Zhujiang Hospital. We would like to thank Ms He Yingzi for the data assistance, Ms Duan Yongtao for the statistical support, and Dr. Annie 
N. Gao for her help with the preparation of this manuscript.

\section{REFERENCES}

[1] Greinix, H.T., Loidolt, H., Rabitsch, W., Schulenburg, A., Keil, F., Mitterbauer, M., Laczika, K., Lechner, K., Dieckmann, K., Fischer, G., Jäger, U., Rosenmayr, A., Knöbl, P., Schwarzinger, I., Höcker, P., Mannhalter, C., Hinterberger, W., Haas, O.A., Fonatsch, C. and Kalhs, P. (2000) Excellent disease eradication by myeloablative therapy and stem-cell transplantation in patients with acute myelogenous leukemia. Annals of Hematology, 79, 206-213. doi: $10.1007 / \mathrm{s} 002770050580$

[2] Abou-Mourad, Y.R., Lau, B.C., Barnett, M.J., Forrest, D.L., Hogge, D.E., Nantel, S.H., Nevill, T.J., Shepherd, J.D., Smith, C.A., Song, K.W., Sutherland, H.J., Toze, C.L. and Lavoie, J.C. (2010) Long-term outcome after allo-SCT: Close follow-up on a large cohort treated with myeloablative regimens. Bone Marrow Transplantation, 45, 295-302. doi:10.1038/bmt.2009.128

[3] Fung, H.C., Stein, A., Slovak, M., O'donnell, M.R., Snyder, D.S., Cohen, S., Smith, D., Krishnan, A., Spielberger, R., Bhatia, R., Bhatia, S., Falk, P., Molina, A., Nademanee, A., Parker, P., Rodriguez, R., Rosenthal, J., Sweetman, R., Kogut, N., Sahebi, F., Popplewell, L., Vora, N., Somlo, G., Margolin, K., Chow, W., Smith, E. and Forman, S.J. (2003) A long-term follow-up report on allogeneic stem cell transplantation for patients with primary refractory acute myelogenous leukemia: Impact of cytogenetic characteristics on transplantation outcome. Biology of Blood and Marrow Transplantation, 9, 766-771. doi:10.1016/j.bbmt.2003.08.004

[4] Petersdorf, E.W. (2008) Optimal HLA matching in hematopoietic cell transplantation. Current Opinion in Immunology, 20, 588-593. doi:10.1016/j.coi.2008.06.014

[5] Szydlo, R., Goldman, J.M., Klein, J.P., Gale, R.P., Ash, R.C., Bach, F.H., et al. (1997) Results of allogeneic bone marrow transplants for leukemia using donors other than HLA-identical siblings. Journal of Clinical Oncology, 15, 1767-1777.

[6] Hahn, T., McCarthy Jr., P.L., Zhang, M.J., Wang, D., Arora, M., Frangoul, H., et al. (2008) Risk factors for acute graft-versus-host disease after human leukocyte antigen-identical sibling transplants for adults with leukemia. Journal of Clinical Oncology, 26, 5728-5734. doi:10.1200/JCO.2008.17.6545,

[7] Russell, J.A., Turner, A.R., Larratt, L., Chaudhry, A., Morris, D., Brown, C., Quinlan, D. and Stewart, D. (2007) Adult recipients of matched related donor blood cell transplants given myeloablative regimens including pretransplant antithymocyte globulin have lower mortality related to graft-versus-host disease: A matched pair analysis. Biology of Blood and Marrow Transplantation, 13, 299-306. doi:10.1016/j.bbmt.2006.10.017

[8] Nash, R.A., Antin, J.H., Karanes, C., Fay, J.W., Avalos, B.R., Yeager, A.M., et al. (2000) Phase 3 study comparing methotrexate and tacrolimus with methotrexate and cyclosporine for prophylaxis of acute graft-versus-host disease after marrow transplantation from unrelated do- nors. Blood, 96, 2062-2068.

[9] Grüllich, C., Ziegler, C. and Finke, J. (2009) Rabbit anti T-lymphocyte globulin induces apoptosis in peripheral blood mononuclear cell compartments and leukemia cells, while hematopoetic stem cells are apoptosis resistan. Biology of Blood and Marrow Transplantation, 15, 173-182. doi:10.1016/j.bbmt.2008.11.014

[10] Remberger, M., Mattsson, J. and Ringd, N.O. (2001) Polyclonal anti-T-cell globulin as part of the preparative regimen for pediatric allogeneic stem-cell transplantation. Pediatric Transplantation, 5, 285-292. doi:10.1034/j.1399-3046.2001.005004285.x

[11] Finke, J., Schmoor, C., Lang, H., Potthoff, K. and Bertz, H. (2003) Matched and mismatched allogeneic stem-cell transplantation from unrelated donors using combined graft-versus-host disease prophylaxis including rabbit anti-T lymphocyte globulin. Journal of Clinical Oncology, 21, 506-513. doi:10.1200/JCO.2003.03.129

[12] Finke, J., Bethge, W.A., Schmoor, C., Ottinger, H.D., Stelljes, M., Zander, A.R., et al. (2011) Standard graftversus-host disease prophylaxis with or without anti-Tcell globulin in haematopoietic cell transplantation from matched unrelated donors: A randomised, open-label, multicentre phase 3 trial. The Lancet Oncology, 10, 855-864. doi:10.1016/S1470-2045(09)70225-6

[13] Mothy, M. and Gaugler, B. (2010) Advances in umbilical cord transplantation: The role of thymoglobulin/ATG in cord blood transplantation. Best Practice \& Research Clinical Haematology, 23, 225-282. doi:10.1016/j.beha.2010.05.004

[14] Soiffer, R.J., Lerademacher, J., Ho, V., Kan, F., Artz, A., Champlin, R.E., et al. (2011) Impact of immune modulation with anti-T-cell antibodies on the outcome of reduced-intensity allogeneic hematopoietic stemcell transplantation for hematologic malignacies. Blood, 117, 69636970. doi:10.1182/blood-2011-01-332007

[15] Kumar, A., Mhaskar, A.R., Reljic, T., Mhaskar, R.S., Kharfan-Dabaja, M.A., Anasetti, C., Mohty, M. and Djulbegovic, B. (2012) Anti-thymocyte globulin for acutegraft-versus-host-disease prophylaxis in patients undergoing allogeneic hematopoietic cell transplantation: A systematic review. Leukemia, 26, 582-588. doi:10.1038/leu.2011.349

[16] Mohty, M., Labopin, M., Balere, M.L., Socie, G., Milpiedl, N., Tabrizi, R., et al. (2010) Antithymocyte globulins and chronic graft vs host disease after myeloablative allogeneic stem cell transplantation from HLA-matched unrelated donors: A report from the Socie te Francaise de Greffe de Moelle et de. Therapie Cellulaire Leukemia, 24, 1867-1874. doi:10.1038/leu.2010.200

[17] Podgorny, P.J., Ugarte-Torres, A., Liu, Y., Williamson, T.S., Russell, J.A. and Storek, J. (2010) High rabbit-antihuman thymocyte globulin levels are associated with low likelihood of graft-vs-host disease and high likelihood of posttransplant lymphoproliferative disorder. Biology of Blood and Marrow Transplantation, 16, 915-926. doi:10.1016/j.bbmt.2010.02.027

[18] Devillier, R., Crocchiolo, R., Castagna, L., Fürst, S., El Cheikh, J., Faucher, C., Prebet, T., Etienne, A., Chaban- 
non, C., Vey, N., Esterni, B. and Blaise, D. (2012) The increase from 2.5 to $5 \mathrm{mg} / \mathrm{kg}$ of rabbit anti-thymocyteglobulin dose in reduced intensity conditioning reduces acute and chronic GVHD for patients with myeloid malignancies undergoing allo-SCT. Bone Marrow Transplantation, 47, 639-645. doi:10.1038/bmt.2012.3

[19] Storb, R., Deeg, H.J., Whitehead, J., Appelbaum, F., Beatty, P., Bensinger, W., et al. (1986) Methotrexate and cyclosporine compared with cyclosporine alone for prophylaxis of acute graft versus host disease after marrow transplantation for leukemia. The New England Journal of Medicine, 314, 729-735. doi:10.1056/NEJM198603203141201

[20] Meijer, E., Boland, G.J. and Verdonck, L.F. (2003) Prevention of cytomegalovirus disease in recipients of allogeneic stem cell transplants. Clinical Microbiology Reviews, 16, 647-657. doi:10.1128/CMR.16.4.647-657.2003

[21] Wilson, D.T., Drew, R.H. and Perfect, J.R. (2009) Antifungal therapy for invasive fungal diseases in allogeneic stem cell transplant recipients: An update. Mycopathologia, 168, 313-327. doi:10.1007/s11046-009-9193-9

[22] Przepiorka, D., Weisdorf, D., Martin, P., Klingemann, H.-G., Beatty, P., Hows, J., et al. (1995) Consensus conference on acute GVHD grading. Bone Marrow Transplantation, 15, 825-828.

[23] Bacigalupo, A. (2007) Management of acute graft-versushost disease. British Journal of Haematology, 137, 87-98. doi:10.1111/j.1365-2141.2007.06533.x

[24] Lee, S.J., Vogelsang, G. and Flowers, M.E.D. (2003) Chronic graft-versus-host disease. Biology of Blood and Marrow Transplantation, 9, 215-233. doi:10.1053/bbmt.2003.50026

[25] Wu, B., Guo, K., Song, C., Yang, D.A. and Li, D. (2000) Mixed chimera converted into full donor chimera with powerful graft-versus-leukemia effects but no graft-versushost disease after non-T cell-depleted HLA-mismatched peripheral blood stem cell transplantation. Bone Marrow Transplantation, 26, 691-693. doi:10.1038/sj.bmt. 1702563
[26] Bacigalupo, A., Lamparelli, T., Barisione, G., Bruzzi, P., Guidi, S., Alessandrino, P.E., et al. (2006) Thymoglobulin prevents chronic graft-versus-host disease, chronic lung dysfunction, and late transplant-related mortality: Longterm follow-up of a randomized trial in patients undergoing unrelated donor ransplantation. Biology of Blood and Marrow Transplantation, 12, 560-565. doi:10.1016/j.bbmt.2005.12.034

[27] Kumar, A., Mhaskar, A.R., Reljic, T., Mhaskar, R.S., Kharfan-Dabaja, M.A., Anasetti, C., Mohty, M. and Djulbegovic, B. (2012) Antithymocyte globulin for acutegraft-versus-host-disease prophylaxis in patients undergoing allogeneic hematopoietic cell transplantation: A systematic review. Leukemia, 26, 582-588. doi:10.1038/leu.2011.349

[28] Kim, H.J., Min, W.S., Cho, B.S., Eom, K.S., Kim, Y.J., Min, C.K., Lee, S., Cho, S.G., Jin, J.Y., Lee, J.W. and Kim, C.C. (2009) Successful prevention of acute graftversus-host disease using low-dose antithymocyte globulin after mismatched, unrelated, hematopoietic stem cell transplantation for acute myelogenous leukemia. Biology of Blood and Marrow Transplantation, 15, 704-717. doi:10.1016/j.bbmt.2009.02.010

[29] Mohty, M., Labopin, M., Balere, M.L., Socie, G., Milpied, N., Tabrizi, R., et al. (2010) Antithymocyte globulins and chronic graft vs host disease after myeloablative allogeneic stem cell transplantation from HLA-matched unrelated donors: A report from the Socie te Francaise de Greffe de Moelle et de. Therapie Cellulaire Leukemia, 24, 1867-1874. doi:10.1038/leu.2010.200

[30] Bredeson, C.N., Zhang, M.J., Agovi, M.A., Bacigalupo, A., Bahlis, N.J., Ballen, K., Brown, C., Chaudhry, M.A., Horowitz, M.M., Kurian, S., Quinlan, D., Muehlenbien, C.E., Russell, J.A., Savoie, L., Rizzo, J.D. and Stewart, D.A. (2008) Outcomes following HSCT using fludarabine, busulfan, and thymoglobulin: A matched comparison to allogeneic transplants conditioned with busulfan and cyclophosphamide. Biology of Blood and Marrow Transplantation, 14, 993-1003. doi:10.1016/j.bbmt.2008.06.009 